\title{
BARRIERS TO REINTEGRATION: An Audit Study of the Impact of Race and OfFEnder Status on EMPlOyMENT OPPORTUNITIES FOR WOMEN
}

\author{
Sarah Wittig Galgano \\ Carnegie Mellon University
}

Previous research has illustrated that the stigma of a criminal record can severely impede employment opportunities for exoffenders, especially African American men, however there is very little research examining how women are affected by criminal records. I expand upon prior research by testing the effects of criminal history and race on female employment prospects. I predict that as research has shown for men, race will present a significant barrier for women seeking to find employment and further predict that a criminal history will be even more stigmatizing for women than it is for men. To test these predictions I employed an audit methodology and submitted fictitious resumes to Chicago-land employers for entry-level jobs. I then compared employer callback rates to test the separate and combined effects of race and criminal history. Results indicate that a prior criminal history had little impact on employer response rates (the white female without a criminal record received responses to $19 \%$ of the jobs applied for, the white female with a criminal record 14\%, the African American female without a criminal record 14\%, and the African American female with a criminal record $12 \%$ ). Results initially indicated that race had no significant impact on employer response rates. Due to the continuing decline of the economy over the data collection period I ran tests to compare data collected prior to the midpoint of data collection to that collected after the midpoint. The results were weak evidence for racial disparity (favoring white applicants) over the first half of the data collection period suggesting that future research should investigate whether African American women in 
healthier economies face greater adversity in the hiring process than their Caucasian counterparts.

\section{Introduction and Background}

Recent research has focused on the impact of a criminal history on employment prospects for African American and white men, and it typically finds that the presence of a criminal record may create additional obstacles for a population most in need of gainful employment (Pager 2003; Pager, Western, and Sugie 2009; Uggen 2000). However, little research has examined the affect of a criminal record on female employment. This study tests employer responses for African American and white women (both with and without a criminal history) to discern whether a criminal history carries the same stigma for women that it does for men.

White applicants' advantage over African-American applicants' when applying for jobs has been repeatedly documented using many different methodologies, but for the purposes of this paper I will focus on studies which employed the audit method. An early audit study, performed by Bendick, Jackson, and Reinoso (1994), used male and female African-American and white testers with equivalent backgrounds (school, work experience, etc) to compare how employment offers differed between African American and white job candidates. After being granted an interview, they found that $47 \%$ of white applicants were offered the position versus only $11 \%$ of blacks, with African-American women experiencing slightly more employer prejudice than African-American men. Using a correspondence methodology, Bertrand and Mullainathan (2004) found that employers responded to one out of ten resumes with white-sounding names where they responded to only one out of every fifteen with African American-sounding names, even when skill levels and education were held constant. Furthermore, Bertrand and Mullainathan (2004) found that enhancing the qualifications of an applicant solely benefited whites, meaning that African Americans with better credentials may experience even greater employer prejudice.

One of the most influential audit studies focusing on how race and offender status impact individuals entering the job market was 
performed by Devah Pager in 2003. Pager found that white males with a criminal record received twice as many employer callbacks as African American males without a criminal record, illustrating how salient of a factor race still may be in employer responses. Pager's study also found that criminal histories have detrimental effects on job opportunities for ex-offenders by revealing that whites without a criminal record received twice as many employer callbacks as whites with a criminal record. Additionally, she found that the impact of a criminal history is even more deleterious for African Americans, as those without a criminal record received approximately three times the number of callbacks as those with a criminal history (Pager 2003).

Employment outcomes are important because of their many positive effects on the lives of ex-offenders. For example, the impact of employment on offender recidivism has been of interest to researchers for decades. While the precise causal relationship between the two variables remains uncertain, there is a clear correlation between gainful employment and reduction in future criminal acts, which is especially apparent when offenders are hired for high quality jobs (Agnew 2005; Laub and Sampson 2003; Sampson and Laub 1990; Uggen 2000; Wright and Cullen 2004).

In addition to reducing criminal activity, obtaining and sustaining employment is often a standard condition for probation or parole. Over five million people were under community supervision at the end of 2007, and for such individuals employment is essential for retaining freedom and for fulfilling the restitution component of parole (Bureau of Justice Statistics, 2008). ${ }^{1}$

Though employment appears to be beneficial in the lives of exoffenders, research has found that the presence of a criminal record may create an obstacle for these individuals. According to Holzer, Raphael, and Stoll's survey of approximately 3,000 companies, employers exhibit more reservations about hiring ex-offenders than any other group they were asked about, which included welfare recipients, individuals with holes in their work experience, and

\footnotetext{
${ }^{1}$ Travis, Soloman, and Waul (2001) note that parole violations account for onethird of national prison admissions, with two-thirds of this group incarcerated for a technical violation versus a new law violation
} 
those whose highest educational attainment was a G.E.D. (2002). Such skepticism about hiring individuals who have been incarcerated may stem from legal restrictions against hiring certain types of ex-offenders for certain job types, the spotty work histories such individuals tend to exhibit, concern about the integrity and work ethic of ex-offenders, or fear of being accused of negligent hiring if an ex-offender commits a criminal act against another individual while on work premises (Holzer, Raphael, and Stoll, 2002).

Ex-offenders have also been found to spend significantly more time not working then men who have never been incarcerated. Using data from the National Longitudinal Survey of Youth, Western (2006) argues that ex-offenders have significantly lower employment rates than those with no prior record. He found that African-American and Hispanic men with criminal records worked approximately $15 \%$ fewer weeks each year than those without a criminal record and a criminal history resulted in about a $10 \%$ reduction in employment for whites.

While research has established that the presence of a criminal record creates an obstacle for offenders trying to obtain employment, a vast majority of the research has focused exclusively on men. In mid-2008, almost 1.5 million men were wards of state or federal prisons, while only 115,779 women fell under their supervision (Bureau of Justice, 2008) and such statistics may help explain why the social sciences have focused their research almost exclusively on men. However, the repercussions of a criminal record on women's employment prospects demand the attention of researchers due to their increasing representation within the criminal justice system. By 2000 , men's incarceration rates had increased by $77 \%$ over the past twenty years, whereas women's had increased by $108 \%$ (Bureau of Justice, 2001). Female ex-offenders are also often supporting children, further increasing their need for employment. The Bureau of Justice (2004) found that over 50\% of state and over $60 \%$ of federal prisoners report having at least one child. Another reason that research needs to examine women's attempts to reenter the labor market is that mothers in state prisons are also three times more likely to report being a single parent than fathers and over half of mothers in jail claim that they are the family's primary source of financial 
support (Bureau of Justice, 2004). Women also differ from men in that they are more likely to re-enter society and tend to do so sooner then men (Sentencing Reform Project, 2006). They are more likely to be convicted of a nonviolent crime, such as a drug (29\% vs. $19 \%$ of the national state prison population) or property offenses $(31 \%$ vs. $20 \%$ of the total national prison population at the state level), than their male counterparts (Bureau of Justice Statistics, 2006).

One recent study has examined women's employment experiences after a period of incarceration in Cook County, Illinois. In 2008 Lalonde and Cho examined how disadvantaged women (of whom 66\% were African American) faired in the employment market and found that a criminal record did not harm the women's employment rates. The researchers found that for the first six months the women's post-incarceration employment rates were approximately four points higher than expected levels (based on the women's pre-incarceration employment rates). The present study adds to Lalonde and Cho's findings in that it examines the effect that race may play in employment opportunities and that it measures employer behavior in an attempt to discern, with all else held equal, how employers differentiate between African American and white females both with and without a criminal history.

Furthermore, since this study employs an audit methodology, I control for differences between ex-offenders and those who have never been incarcerated by creating equivalent work histories and backgrounds which allow me to isolate the effect of offender status and race on employment outcomes.

\section{Data \& Methods}

This study tested the effect of race and previous incarceration on employer responses to female applicants using a correspondence approach ${ }^{2}$, which involved the use of four resumes constructed for

\footnotetext{
${ }^{2}$ Audit studies, a form of field experiments, are one method for overcoming the difficulties inherent in measuring discrimination because they retain the strengths of experiments, but apply them to real world conditions (Pager, 2007). There are two major types of audit studies: correspondence testing (which uses resumes to convey the information under study) and in-person audit studies (which use actual applicants to directly present relevant information to employers and report
} 
four fictitious female job applicants, two of whom were African American and two white. The dependent variable in this study was employer callback and the independent variables were race and offender status. Like Pager's (2003), the applicants were split into dyads based on race with both white applicants applying to one set of jobs and both African Americans applying to a second set of jobs.

I constructed four resumes based on actual resumes that were obtained from the University of Iowa's Career Center. Two different resume templates per racial pairing were used so that employers would not suspect they were getting applications from the same person. In addition to using different templates, the font was varied to divert employers from discovering similarities between the applicant's profiles and resumes.

Each applicant's educational and work experiences were made comparable. Bureau of Justice Statistics (2003) show that 58\% percent of women in state prisons have at least a high school diploma or its equivalent, so each applicant listed a high school diploma as their highest educational achievement. The resumes also reflected similar and very positive work experiences for all four applicants, with one member of each pair reporting experience in an assistant managerial capacity at a popular national chain restaurant for one and one-half years, and the other female in the pair reporting the same amount of time in an assistant manager position at a large hardware store. The only major differences between the resumes were the presence of a criminal record and race. Since the fictitious

their experiences afterwards to researchers). According to Pager (2007), the main advantage of correspondence audit testing is that allows researchers to maintain complete control however it does rely on employers to observe and interpret relevant data. In-person studies can create a larger job base since jobs which require the applicant to present themselves to the potential employer can be included.

Time constraints prevented the use of in-person from being considered for the present study, but data collection revealed that using the correspondence approach offered some significant advantages. Many of the jobs posted in the Chicago Tribune require the applicant to apply using their online employment service rather than applying in person, so using the correspondence approach actually broadened the number of entry-level positions that could be included. Furthermore, CareerBuilder.com specifically asks applicants if they have been convicted of a felony when signing up to use their services which made the employers in this study aware of the applicants' criminal histories. 
women were not presenting themselves directly to employers it was necessary to convey a criminal history within the job history portion of the resume by stating six months experience working in the kitchen of the Mitchellville Correctional Institute for Women (a maximum security prison for women). To further reflect the presence of a criminal history a fictitious probation officer was used as a personal reference on the resume. Prior research has established these strategies as reliable means of providing evidence of time spent in prison that are utilized by actual ex-offenders to justify gaps in their work experience and to attest that they have changed their ways (Pager 2003).

Since the fictitious applicants were not presenting themselves to the employers in person it was necessary to convey race by using "ethnic sounding" names. Names were selected from prior research by Bertrand and Mullainathan (2004), who surveyed individuals in Chicago to determine which names were most frequently associated with whites and which were most often perceived as African American. Bertrand and Mullainathan's (2004) study listed the nine names most often associated with each race. From each list two names were selected for the purpose of this study. Lakisha and Aisha were perceived as African American approximately 97\% of the time and Laurie and Kristin were perceived as white approximately $97 \%$ of the time according to Bertrand and Mullainathan (2004). ${ }^{3}$

In order to monitor employer responses and create a realistic applicant profile I purchased four cellular phones and set up voicemail boxes for each fictitious applicant using Chicago area phone numbers. One additional phone was purchased and used as a voicemail box for the probation officer who was listed as a reference for the applicants with a criminal record. A prerecorded voice message was used so that I only had to state the applicant's first and last name (in an even tone) in the middle of a prerecorded message saying that the applicant was not available to answer the

\footnotetext{
${ }^{3}$ The last names used in this study were also selected from Bertrand and Mullainathan's (2004) study based on their association with a specific racial group. Walsh and Baker were used for the white applicants while Washington and Jones were selected for the African American applicants.
} 
phone. Chicago addresses were obtained for the resumes in student populated areas of Chicago in an effort to convey lower income to employers who might be familiar with the addresses listed on the resumes. While mail correspondence was not anticipated (and did not occur), addresses from Chicago students who lived in areas mixed ethnicity were solicited in the event any correspondence would be sent. Four e-mail addresses were set up using portions of the applicants first and last names to provide an additional method of monitoring employer responses. To monitor employer response rates the job category, date applied, and names were recorded.

Job postings were gathered using CareerBuilder.com, which is the Chicago Tribune's preferred method of online employment advertising. Resumes were submitted from August 2008 to early November 2008. Entry level jobs from seven categories were used: administrative/clerical, hospitality/hotel, customer service, restaurant, grocery, retail, and sales. The two racial dyads applied for the same number of jobs from each category so as to provide reliable comparisons. Any job which asked the applicant to call, appear in person, or fax in a resume were excluded, however a vast majority of the jobs advertised on CareerBuilder.com were not excluded from the study based on these restrictions. Only those jobs which allowed applicants to submit their application via CareerBuilder. com or fill out an application asking questions which could be answered using only information from the fictitious applicants resume were used. For each job two resumes were submitted from the racial dyad (either the whites applied for the job or the African Americans applied for the jobs) with an accompanying cover letter stating the applicant's name and phone number for future contact. Resumes were submitted within two days of each other, but never on the same day to minimize suspicion. The only notable difference between the applicants was the presence of a criminal record that was reflected both on the resume and by answering yes to the statement "I have been convicted of a felony in the U.S." on Careerbuilder's website. ${ }^{4}$ To convey that the applicant was a first time

\footnotetext{
${ }^{4}$ Felony conviction was the only information passed on to employers regarding the type of offense the applicant was found guilty of since the nature of the correspondence method made it impossible to inform employers exactly which type
} 
offender only a single work experience within the prison system was listed and there were no significant gaps in their employment history following their first employment experience.

To measure employer response I monitored email correspondence and telephone calls. A response was considered positive if the employer, either via e-mail or phone call, solicited an interview from one of the applicants. A response was deemed negative if the employer stated they were not interested in further contact with the applicant, either by stating that the position was already filled or that the applicant was not being considered for the position, or if the applicant did not receive any response from the employer.

\section{Table 1. Job Types}

\begin{tabular}{|lcc|}
\hline Type of Job & Count & Percent \\
Customer Service & 357 & $59 \%$ \\
Administrative/Clerical & 88 & $15 \%$ \\
Restaurant & 68 & $11 \%$ \\
Retail & 40 & $7 \%$ \\
Hospitality/Hotel & 24 & $4 \%$ \\
Grocery & 8 & $1 \%$ \\
Sales & 16 & $3 \%$ \\
\hline
\end{tabular}

\section{Results}

Each applicant submitted a resume for 150 jobs so that a total of 600 resumes were submitted for 300 different employment opportunities over approximately a three month period. ${ }^{5}$ Table 2 shows that customer service jobs accounted for approximately $60 \%$ of the total job applications $(\mathrm{N}=357)$, administrative and clerical jobs accounted for $15 \%(\mathrm{~N}=88), 11 \%$ were restaurant jobs $(\mathrm{N}=$ $66)$, and $7 \%$ were retail jobs $(\mathrm{N}=40)$. Hospitality/hotel work, sales jobs, and grocery work combined accounted for less than $10 \%$ of the total jobs applications.

of crime the applicant was found guilty of (i.e. drug offense, robbery, etc).

${ }^{5}$ One applicant was directly contact by a potential employer requesting an interview which brought the total number of jobs to 601 . 
Table 2. Callback Rate By Race and Category

\begin{tabular}{|lcc|}
\hline Type of Job & African American & White \\
Customer Service & $10 \%$ & $16 \%$ \\
Administrative/Clerical & $23 \%$ & $16 \%$ \\
Restaurant & $24 \%$ & $9 \%$ \\
Retail & $10 \%$ & $10 \%$ \\
Hospitality/Hotel & $0 \%$ & $20 \%$ \\
Grocery & $0 \%$ & $25 \%$ \\
Sales & $25 \%$ & $50 \%$ \\
\hline
\end{tabular}

The total range of response time extended from hearing back from potential employers on the same day that the application was submitted to twenty days after applying. Applicants received most employer requests for interviews $(75 \%)$ within six days of submitting their application, with the majority of employers initiating contact within twenty-four hours of receipt.

\section{Is there a Racial Disparity in Response Rates?}

Unlike prior research which has found that white males have a major advantage over African American males, a chi square test showed no significant difference in employer response to female applicants by race. The mean callback rate over all the women was 0.15 . White applicants had a positive response rate of 0.17 and African Americans had a rate of 0.13 . However, when comparing the response rates from the first 300 applications to the final 300 applications I found weak (though not significant at $\mathrm{p}<0.05$ ) evidence $(\mathrm{p}<0.10)$ for racial differences in early response rates (with whites exhibiting an advantage over African American women for the first seventy-five job applications). After the application midpoint the racial differences in employer response rates dropped further. Employer response rates overall dropped off across all applicants as well after the midpoint in data collection. ${ }^{6}$ Before the application

\footnotetext{
${ }^{6} \mathrm{I}$ also performed a logistic regression to regress employer responses on exoffender status, race, job type, and the month the applicants' resume was submitted. Results from this multivariate approach fail to find support for a direct effect of race on "callbacks". I also continue to find no support for a direct effect of prior
} 


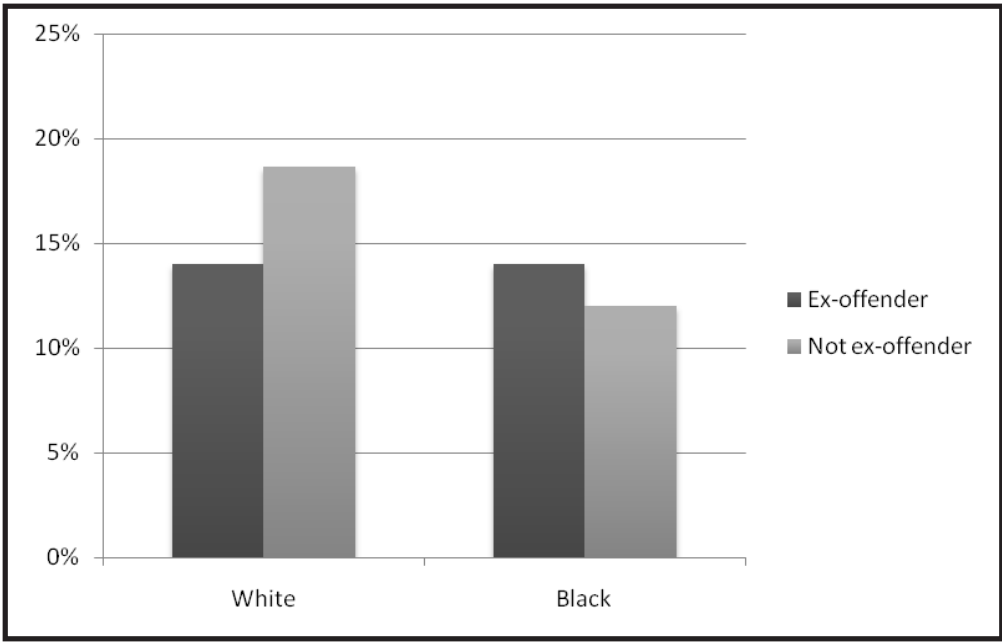

Figure 1. Employer Response Rates by Race and Offender Status

midpoint, $19 \%$ of applications received positive responses, but after the midpoint, $11 \%$ received positive responses.

Racial differences were found within three of the four most commonly available job categories. Though there was no difference between African Americans and whites in the retail category (each group received responses to $10 \%$ of jobs applied for), African Americans were advantaged in restaurant careers (with a $24 \%$ positive response rate versus whites who received positive responses to 9\%). African Americans also received a higher percentage of positive responses from employers in the administrative/clerical field, receiving positive responses to $23 \%$ of the positions applied for in this category whereas whites received positive responses to approximately $16 \%$. The only job category where whites showed a distinct advantage was in the customerservice field. Whites applying for customer-service positions received positive responses to $16 \%$ of the customer service positions they applied for, whereas African Americans received such responses only $10 \%$ of the time. It is important to note that the

criminal record on the probability of employer response. For these reasons, the results from the logit model are not presented, but are available from the author by request. 


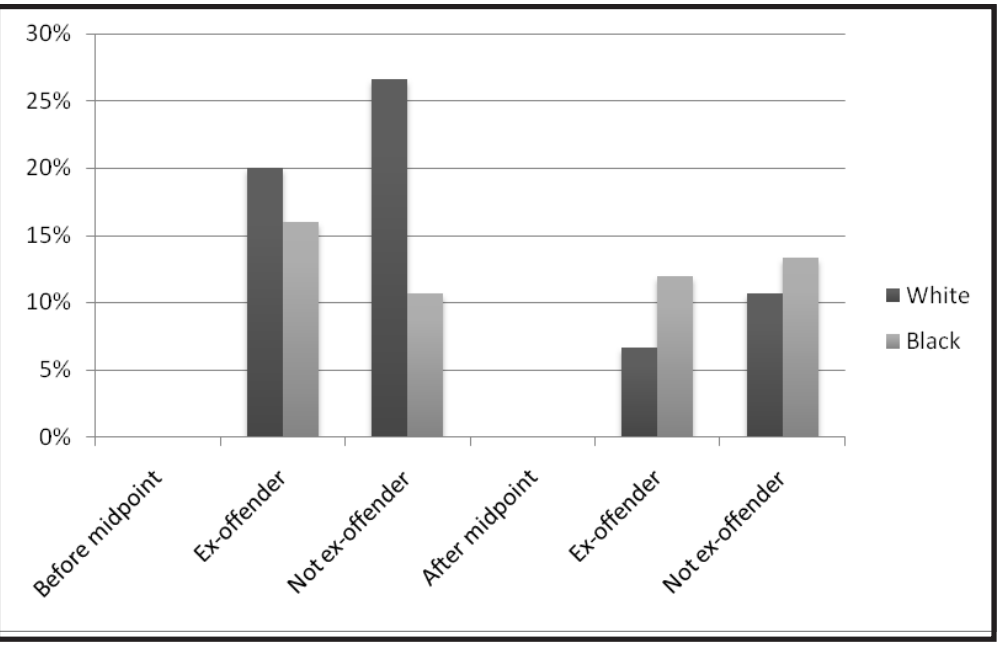

Figure 2. Employer Response Rates Before and After Midpoint (September 14, 2008)

majority of the available jobs for which applicants in this study were qualified were customer-service positions, which is reflected in the fact that these positions constituted $60 \%$ of the total job applications. The disadvantage faced by African Americans in this job market sector is magnified by the fact that jobs in this area dominate the entry-level positions available in the Chicago area.

Does the Presence of a Criminal Record Impact Response Rates?

The response rates collected indicate that employers do not discriminate against women with criminal backgrounds. Non-offenders received responses to 46 of the 300 jobs applied for across all job types (15\%), and ex-offenders received responses to 41 of the total 300 jobs applied for across all job types (14\%). White applicants with a criminal record received responses to $19 \%$ of the jobs applied for and those with a criminal record had a response rate of 15\%. African American without a criminal record had a slightly smaller response rate (12\%) versus African American women with a criminal record (who received responses to $15 \%$ ). 
Unlike the racial differences, chi square tests run to compare employer response rates before and after the midpoint of data collection found no differences between response rates for women with a criminal record versus those with no prior criminal history. Comparing the effect of criminal history within job categories also yielded no significant results in any of the job categories.

\section{Discussion and Conclusions}

Several studies, performed at different times and in different locations, have found that the presence of a criminal record creates a significant barrier for men seeking employment and some have found that this stigma is even greater for African-American men than it is for whites (Pager 2003; Pager, Western, and Sugie 2009; Uggen 2000). This study found that a criminal history is not as universally stigmatizing for women, although it is important to remember that this study's results are specific to time and place and therefore need to be confirmed in other economic contexts and employment markets. This finding supports the claims of feminist criminologists who assert that to focus exclusively on the male experience of the criminal justice system and its consequences is to lose sight of the entire picture (Daly and Chesney-Lind 1988; Morris 1987). Studies that singularly focus on men lead to a single set of assumptions that become generalized to the entire population. However this study shows that ignoring women, or worse yet assuming they affected the same manner as men by a criminal record, is a grave mistake as it seems that their experiences in the labor market are markedly different from men's and therefore merit the attention of researchers for policy and practice purposes.

The findings from the present study are consistent with Lalonde and Cho's (2008) study of actual offenders. These similar findings, even given the differences between the studies, suggest that women with a prior criminal record may face less discrimination from potential employers than men face. One reason this difference between the sexes may exist could be that women are far more likely to be imprisoned for a nonviolent crime than males (Sentencing Reform Project 2006) which may make a criminal history less stigmatiz- 
ing in the eyes of potential employers. Another reason may be simply that the demands of the labor market are more favorable to women seeking entry-level positions than men. Among employed women in 2008, the most common job category was administrative positions, the fifth most common was retail, eighth was restaurant work, and the ninth most common positions were receptionists and information clerks, which were included under customer service in this study (United States Department of Labor, 2009). These four entry-level jobs were the most common types found and applied for by the fictitious female applicants in this study and, since they were dominated by women, the gender of the applicants was perhaps an asset from which neither race nor criminal record could detract. ${ }^{7}$

A portion of the drop-off in employer responses over the last half of data collection may be attributable to the continuous decline of the American economy and the subsequent reduction in employment opportunities. Over the last six months of 2007 the U.S. economy spiraled downward until it finally entered a recession in December that continued throughout the following year (National Bureau of Economic Research, 2008). According to the Bureau of Labor Statistics (2008) the unemployment rate within Chicago rose by $1.7 \%$ from $4.6 \%$ in November of 2007 to $6.3 \%$ in November of 2008. Additionally, Chicago suffered from a loss of 34,400 payroll jobs over the same time period, making the city the metropolitan area in the state hardest hit by the economic decline (Illinois Department of Employment Security 2008). ${ }^{8}$ In 2008 the national unemployment rate rose from its low of $4.9 \%$ in the first quarter to a high of $6.9 \%$ in the final quarter of the year (Borbely, 2009). Service occupations rose on the national level from November 2007 to November 2008 (with women accounting for a majority of the growth in this field) while office and administrative positions fell by a staggering 909,000 of which 906,000 were women (Borbely,

\footnotetext{
${ }^{7}$ Interestingly, retail is the only occupation type that is included on both men's $\left(6^{\text {th }}\right)$ and women's $\left(5^{\text {th }}\right)$ top ten lists. Physical labor and positions requiring the supervision of others dominated the list of most commonly held jobs by men in 2008 (Unites States Department of Labor, 2009).

${ }^{8}$ Rockford, IL came in second with a loss of 1,500 payroll jobs, or $4 \%$ of the total number of jobs lost in Chicago (Illinois Department of Employment Security, 2008).
} 
2009). Labor statistics show that the unemployment rate among white women was $4.9 \%$ while for African-Americans women it was 8.9\% (United States Department of Labor, 2009). Numerous studies have found that recessions tend to affect African Americans (and other minorities) at disproportionate levels suggesting that were this study conducted later in the economic downturn the findings may have indicated a significant disadvantage for African Americans (Gardner 1993; Langdon 2002; McMenamin, Krantz, and Krolik 2002; and Schmitt and Baker 2008).

This study provides evidence that a criminal record does not have the stigmatizing effect for women that it does for men. However, before these results can be generalized additional research into this area of study must be performed. One important limitation of this study is that it may only reflect the attitudes of Chicago area employers and not those of other employers in different geographic locations and different economic contexts around the country. Another limitation of this study is that it could have fallen victim to a hazard of correspondence studies; it excluded jobs in Chicago that required applicants to appear in-person to pick up an application or drop off resumes. Also, the recession occurring at the time of data collection could limit the generalizability of the current study.

Future research should examine how both men and women are affected by race and offender status at the same time and in the same location so that direct comparisons can be drawn between the two sexes.

\section{References}

Agnew, Robert. 2005. Why do Criminals Offend? A General Theory of Crime and Delinquency. Los Angeles: Roxbury.

Bendick, M., Jackson, C., and Reinoso, V. (1994). "Measuring Employment Discrimination through Controlled Experiments." Black Political Economy. 23: 25-48.

Bertrand, M. and Mullainathan, S., 2003. "Are Emily and Greg More Employable Than Lakisha and Jamal? A Field Experiment on Labor Market Discrimination." American Economic Review, 94(4): 991-1013.

Borbely, J., 2009. "U.S. Labor Market in 2008: Economy in Recession". Washington D.C.: Monthly Labor Review, Bureau of Labor Statistics. 
Bureau of Justice Statistics (2001), Criminal Offenders Statistics. Washington D.C.: Bureau of Justice Statistics, U.S. Department of Justice.

—. 2003. Education and Correctional Populations. Washington D.C.: Bureau of Justice Statistics, U.S. Department of Justice.

—. 2004. Parents in Prison and Their Minor Children. Washington D.C.: Bureau of Justice Statistics, U.S. Department of Justice.

—. 2006. Prisoners in 2006, Washington D.C.: Bureau of Justice Statistics, U.S.

Department of Justice.

—. 2008. Census of State and Federal Correctional Facilities, 2005. Washington D.C.: Bureau of Justice Statistics, U.S. Department of Justice.

—. 2008. Probation and Parole Statistics, Washington D.C.: Bureay of Justice Statistics, U.S. Department of Justice.

Bureau of Labor Statistics. 2008. http://www.bls.gov/eag/eag.us.htm (accessed 01/06/2009)

Daly, K. and Chesney-Lind, M. 1988. "Feminism and Criminology." Justice Quarterly 5(4):101-143.

Gardner, J., 1993. "Recession swells count of displaced workers". Washington D.C.: Monthly Labor Review, Bureau of Labor Statistics.

Holzer, H., Rapael, S., and Stoll, M. 2002. "Will Employers Hire ExOffenders? Employer Preferences, Background Checks, and Their Determinants." in The Impact of Incarceration on Families and Communities, edited by M. Pattillo, D. Weiman, and B. Western. New York: Russell Sage Foundation.

Illinois Department of Employment Security (2008).

http://www.ides.state.il.us/economy/laus.pdf (accessed 01/06/2009).

Langdon, D., McMenamin, T., and Krolik, T., (2002). "U.S. Labor Market in 2001: Economy Enters a Recession." Monthly Labor Review, Bureau of Labor Statistics.

Lalonde, R., and Cho, Rosa. 2008. "The Impact of Incarceration in State Prison on the Employment Prospects of Women." Journal of Quantitative Criminology, 24: 243-265.

Laub, John L., and Robert J Sampson. 2003. Shared Beginnings, Divergent Lives: Delinquent Boys to Age 70. Cambridge, MA: Harvard University Press.

McMenamin, T., Krantz, R., and Krolik, T. 2002. "U.S. Labor Market in 2002: Continued Weakness." Monthly Labor Review, Bureau of Labor Statistics.

Morris, A. 1987. Women, Crime, and Criminal Justice. NY: Basil Blackwell. 
National Bureau of Economic Research. 2008. Determination of the December 2007 Peak Activity. www.nber.org/dec2008.pdf (accessed 9/15/2009).

Pager, D., 2003. "The Mark of a Criminal Record." American Journal of Sociology, 108 (5) 937-75.

- 2007. "The Use of Field Experiments for Studies of Employment Discrimination: Contributions, Critiques, and Directions for the Future." The ANNALS of the American Academy Society of Political and Social Science, 609: 104-33.

Pager, D., Western, B., and Sugie, N. 2009. "Sequencing Disadvantage: Barriers to Employment Facing Young Black and White Men with Criminal Records." The ANNALS of the American Academy of Political and Social Science, 623: 195-213.

Sampson, R., \& Laub, J. 1990. Crime in the Making: Pathways and Turning Points Through Life. Harvard University Press, Cambridge, MA.

Schmitt, J., and Baker, D. 2008. What we're in For: Projected Economic Impact of the Next Recession. Washington D.C.: Center for Economic Policy and Research.

Sentencing Reform Project, 2006. New Incarceration Figures: ThirtyThree Years of Growth. Washington D.C.: The Sentencing Project.

Travis, J., Soloman, A., \& Waul, M. 2001. From Prison to Home: The Dimensions and Consequences of Prisoner Reentry. Washington D.C., The Urban Institute. Uggen, C., (2000). "Work as a Turning Point in the Life Course of Criminals: A Duration Model of Age, Employment, and Recidivism." American Sociological Review, 65: 529-46

United States Department of Labor, (2009). http://www.dol.gov/wb/stats/ main.htmAccessed 9/10/2009.

—. 2009. http://www.bls.gov/cps/cpsaat39.pdf. Accessed 9/10/2009.

Western, Bruce. 2006. Punishment and Inequality in America. New York: Russell Sage Foundation.

Wright, John Paul, and Francis T. Cullen. 2004. "Employment, Peers, and Life-Course Transitions.” Justice Quarterly 21:183-205 